\title{
Communicating With Patients Who Have Nonbinary Gender Identities
}

Hilary Goldhammer, $S M^{1}$

Sula Malina, $B A^{2}$

Alex S. Keurogblian, $M D, M P H^{1,3,4}$

'National LGBT Health Education Center at The Fenway Institute, Fenway Health,

Boston, Massachusetts

${ }^{2}$ Human Rights Campaign Foundation, Washington, DC

${ }^{3}$ Massachusetts General Hospital, Boston, Massachusetts

${ }^{4}$ Harvard Medical School, Boston, Massachusetts

Conflicts of interest: authors report none.

\section{CORRESPONDING AUTHOR}

Alex S. Keuroghlian, MD, MPH

The Fenway Institute

1340 Boylston Street

Boston, MA, 02215

akeuroghlian@partners.org

\begin{abstract}
The increasing visibility of transgender people and others who do not conform to traditional gender norms challenges us to think about gender in new ways, and to use new terminology when communicating with patients. People who describe themselves as nonbinary have a gender identity that is not exclusively girl/woman or boy/man. A small but growing body of research indicates they experience high levels of societal victimization and discrimination, and are misunderstood by health care clinicians. Using language that is inclusive of all gender identities can reduce these burdens and barriers. In this essay, we use a case scenario that illustrates ways to interact respectfully and affirmatively with nonbinary people throughout the patient care experience.
\end{abstract}

Ann Fam Med 2018;16:559-562. https://doi.org/10.1370/afm.2321.

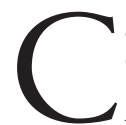
ase Scenario: Sam, aged 22 years:

Sam is about to arrive for a new patient visit at a local health center. As a person with a nonbinary gender identity, Sam is nervous that the experience will not go well. Will the new primary care clinician accept Sam's gender identity or dismiss it as "confusion" like the last clinician did?

Increasingly, health care clinicians see patients like Sam who live openly as nonbinary - an umbrella term that encompasses any gender identity outside of the binary construct of girl/woman or boy/man. Gender identity refers to the inner sense of one's gender, while sex refers to the female or male designation assigned to a newborn based on external anatomy. Some but not all nonbinary people identify as transgender, a term that describes people whose gender identity differs from the one traditionally associated with their sex assigned at birth. ${ }^{1}$ While many transgender people identify their gender as solely girl/woman or boy/man, nonbinary people may identify as both, somewhere in between, something else, and/or reject the concept of gender altogether. Nonbinary people who have a fluctuating gender identity often refer to themselves as gender fluid.

As an underserved population at disproportionate risk for discrimination, victimization, and suicidal ideation, nonbinary people are especially in need of health care clinicians who affirm their gender identities. ${ }^{2-6}$ The medical literature on culturally sensitive care with racial/ethnic minorities as well as sexual and gender minorities recognizes language and communication as fundamental to engendering trust with patients, positively influencing patient satisfaction and adherence, and ultimately improving engagement in care and health outcomes. ${ }^{7.9}$ In this article, we aim to help bridge language and communication gaps between nonbinary people and their health care clinicians by explaining ways to use affirming terms and pronouns while avoiding assumptions about gender. Sam's case scenario illustrates approaches for communicating effectively with nonbinary people throughout the patient care experience.

When Sam arrives at the health center, the registration staff member greets Sam by saying, "Good morning. How may I help you?" Sam is pleased that the staff member does not use any gender-specific terms or identifiers, like "ma'am/sir" or "Ms/Mrs/Mr." 
The registration staff member in Sam's case scenario demonstrates the practice of avoiding gendered terminology when speaking with new patients. It is impossible to know someone's gender identity or pronouns just by hearing their voice or looking at them. Some people wear gender nonconforming clothing and hairstyles, while others dress, speak, and act in ways traditionally associated with either femininity or masculinity. Therefore, by asking "How may I help you?" instead of "How may I help you, ma'am/sir?" the registration staff member reduces the likelihood of offending patients by incorrectly guessing their gender.

Sam is handed a registration form that asks for "name and gender on insurance," the "name on identification documents," and the "name you wish to be called during the office visit." Sam feels relieved to be asked these questions. Sam currently has neither the time nor funds to legally change their name from "Sherilynn" to "Sam." In addition, the form asks for the patient's pronouns, gender identity, and sex assigned at birth. Sam checks off "they/them/theirs" for pronouns, "genderqueer" for gender identity, and "female" for sex assigned at birth.

By collecting information from patients on names, gender identity, and pronouns, this registration form signals to patients of diverse gender identities that the health center's staff will make an effort to address patients in accordance with their wishes..$^{10-13}$ Although Sam identifies as genderqueer, other nonbinary people may use a range of terms to describe themselves (Table 1). ${ }^{14}$ The terminology for nonbinary identities varies from person to person; over time, new terms also emerge while others become outdated. For these reasons, organizations may want to provide patients with a list of gender identity terms as well as the option to write in a term. It is also recommended to offer patients an option to "choose not to disclose."

Using correct pronouns is essential for building a stronger patient-clinician alliance. While Sam's pronouns are they/them/theirs in the singular form, other people may have more traditional pronouns such as she/her/hers and he/him/his, or pronouns such as ze/ hir/hirs that were developed specifically by and for nonbinary people. Some people do not have pronouns at all. Because speaking with unfamiliar (or no) pronouns may at first present a challenge, we developed a chart (Table 2) ${ }^{14}$ as part of our guidelines from the National LGBT Health Education Center that lists pronouns along with phrases commonly used in clinical situations, to adapt for self-directed practice or as part of a workplace training.

Documenting patients' sex assigned at birth in addition to gender identity helps to ensure that insurance will cover screening and treatment related to sex characteristics. Some people may not feel comfortable including this information initially and may need to first build more rapport with their clinician.

Finally, the discrepancy between Sam's name and the name on their insurance is common for people with transgender and nonbinary identities. In situations when a person gives a name that does not match any records, staff can ask, "I'm sorry, could your insurance/chart/ record be under a different name?" The challenge for health care organizations is to not only collect names, pronouns, and gender identity in registration forms, but also to ensure the electronic health record can harness and display this information in ways that are visible to relevant staff. Some software systems have fields already developed for this, while others need modifications. Once systems are in place, staff members will likely require training and practice in order to be able to consistently access and use the names and pronouns provided by patients.

Sam's new primary care clinician, Dr Shaw, refers to Sam as "transgender" while taking a social history. Sam corrects Dr Shaw, explaining that they are genderqueer and do not consider 


\section{Table 2. Examples of Ways to Use Nonbinary Pronouns ${ }^{14}$}

\begin{tabular}{|c|c|}
\hline Pronouns & Sample sentences \\
\hline $\begin{array}{l}\text { They/them/theirs } \\
\text { (refers to an indi- } \\
\text { vidual person) }\end{array}$ & $\begin{array}{l}\text { - They are in the waiting room. } \\
\text { - The doctor is ready to see them. } \\
\text { - They need an appointment for next month. } \\
\text { - Can you order them a prescription? } \\
\text { - That chart is theirs. }\end{array}$ \\
\hline $\begin{array}{l}\text { Ze/hir/hirs (pro- } \\
\text { nounced zeel } \\
\text { hear/hears) }\end{array}$ & $\begin{array}{l}\text { - Ze is in the waiting room. } \\
\text { - The doctor is ready to see hir. } \\
\text { - Ze needs an appointment for next month. } \\
\text { - Can you order hir a prescription? } \\
\text { - That chart is hirs. }\end{array}$ \\
\hline No pronouns & $\begin{array}{l}\text { - [Name] is in the waiting room. } \\
\text { - The doctor is ready to see [Name]. } \\
\text { - [Name] needs an appointment for next month. } \\
\text { - Can you order [Name] a prescription? } \\
\text { - That chart is [Name's]. }\end{array}$ \\
\hline Unsure of pronouns & $\begin{array}{l}\text { "I would like to be respectful. What are your } \\
\text { pronouns?" }\end{array}$ \\
\hline
\end{tabular}

anything covering your chest, as long as that is comfortable for you. If not, that is fine too."

By using terms that apply to all genders and anatomies, like underwear and chest, Dr Shaw affirms Sam's nonbinary gender identity and provides a safe and inclusive health care experience. In addition, Dr Shaw recognizes that Sam may not be comfortable enough with a new clinician to expose their chest, because this may trigger a sense of dysphoria. During the exam, Dr Shaw can ask Sam what terms they use for different parts of their anatomy, and then mirror those terms. ${ }^{16}$

\section{CONCLUSION}

Our culture's increasingly nuanced understanding of gender brings a responsibility for all health care clinicians to support patients' self-definition of their gender identities. Best

themselves transgender. Dr Shaw replies, "I'm sorry, I'm not familiar with the term 'genderqueer' and assumed it was the same as 'transgender.' I appreciate your patience while I learn. Would you be willing to tell me what being genderqueer means to you? If not, that's okay."

When communication missteps occur (early in the learning process, they almost inevitably do), most patients are understanding and show appreciation for the clinician's commitment to learning and practicing new terms and pronouns. In Sam's case, Dr Shaw demonstrates a best practice by offering a brief and sincere apology. Moreover, by asking Sam if they are willing to share more about their identity, Dr Shaw attempts to build rapport and better understand Sam without obligating Sam to act as a teacher. Occasionally, patients will become angry or distressed if called the wrong pronoun, name, or gender. These patients have likely experienced a heavy burden of discrimination in the past that contributes to this reaction. An empathic response could be: "I hear that you are very upset. I apologize, I didn't mean to disrespect you."

Dr Shaw's conflation of the terms genderqueer and transgender stems from the complex nature of gender identities and the nuanced array of related yet distinct terms for these. Nonbinary people may or may not think of themselves as transgender. Additionally, like transgender men and women, nonbinary people sometimes seek hormone therapy or surgeries to affirm their gender identity and to help them feel more aligned in their bodies. ${ }^{1,15}$

After taking Sam's history, Dr Shaw asks Sam to prepare for the physical exam and says, "Please change into this robe, with the opening in the front. You can leave on your bottom underwear but it is better to not have practices for all health care staff include avoiding assumptions about patients' gender identities, asking for information about name and pronouns in order to adopt these consistently throughout the clinical setting, and describing anatomy and related terms with gender-inclusive language. Through these communication approaches, health care clinicians can remain responsive to rapidly expanding concepts and terminology for gender identification and expression within our society, and can offer more patient-centered care that moves beyond binary gender concepts.

To read or post commentaries in response to this article, see it online at http://www.AnnFamMed.org/content/16/6/559.

Key words: communication; cultural humility; gender identity; health disparities; non-binary; nonbinary; primary care; transgender

Submitted June 20, 2018; submitted, revised, September 10, 2018; accepted September 20, 2018.

Funding support: The authors' work was supported by Grant U30CS22742 from the Health Resources and Services Administration Bureau of Primary Health Care and the Horace W. Goldsmith Foundation. The funders were not involved in the writing of the article or in the decision to submit the article for publication.

\section{References}

1. James S, Herman JL, Rankin S, et al. Report of the 2015 U.S. Transgender Survey. Washington, DC: National Center for Transgender Equality; 2016. http://www.ustranssurvey.org.

2. Grant J, Mottet LA, Tanis J, Harrison J, Herman JL, Keisling M. National Transgender Discrimination Survey Report on Health and Health Care. Washington, DC: National Center for Transgender Equality and National Gay and Lesbian Taskforce; 2011. https:// cancer-network.org/wp-content/uploads/2017/02/National_ Transgender_Discrimination_Survey_Report_on_health_and_ health_care.pdf. 
3. Sterzing PR, Ratliff GA, Gartner RE, McGeough BL, Johnson KC. Social ecological correlates of polyvictimization among a national sample of transgender, genderqueer, and cisgender sexual minority adolescents. Child Abuse Negl. 2017;67:1-12.

4. Eisenberg ME, Gower AL, McMorris BJ, Rider GN, Shea G, Coleman E. Risk and protective factors in the lives of transgender/gender nonconforming adolescents. J Adolesc Health. 2017;61(4):521-526.

5. Lykens JE, LeBlanc AJ, Bockting WO. Healthcare experiences among young adults who identify as genderqueer or nonbinary. LGBT Health. 2018;5(3):191-196.

6. Nadal KL, Whitman CN, Davis LS, Erazo T, Davidoff KC. Microaggressions toward lesbian, gay, bisexual, transgender, queer, and genderqueer people: a review of the literature. J Sex Res. 2016; 53(4-5):488-508.

7. Washington DL, Bowles J, Saha S, et al; Writing Group for the Society of General Internal Medicine, Disparities in Health Task Force. Transforming clinical practice to eliminate racial-ethnic disparities in healthcare. J Gen Intern Med. 2008;23(5):685-691.

8. Betancourt JR, Green AR, Carrillo JE, Ananeh-Firempong O II. Defining cultural competence: a practical framework for addressing racial/ethnic disparities in health and health care. Public Health Rep. 2003;118(4):293-302.

9. Rossi AL, Lopez EJ. Contextualizing competence: language and LGBT-based competency in health care. J Homosex. 2017;64(10): 1330-1349.

10. Cahill S, Makadon H. Sexual orientation and gender identity data collection in clinical settings and in electronic health records: a key to ending LGBT health disparities. LGBT Health. 2014;1(1):34-41.
11. Deutsch MB, Green J, Keatley J, Mayer G, Hastings J, Hall AM; World Professional Association for Transgender Health EMR Working Group. Electronic medical records and the transgender patient: recommendations from the World Professional Association for Transgender Health EMR Working Group. J Am Med Inform Assoc. 2013;20(4):700-703.

12. Donald C, Ehrenfeld JM. The opportunity for medical systems to reduce health disparities among lesbian, gay, bisexual, transgender and intersex patients. J Med Syst. 2015;39(11):178.

13. Dunne MJ, Raynor LA, Cottrell EK, Pinnock WJA. Interviews with patients and providers on transgender and gender nonconforming health data collection in the electronic health record. Transgend Health. 2017;2(1):1-7.

14. National LGBT Health Education Center. Providing Affirmative Care for Patients With Non-binary Gender Identities. Boston, MA: National LGBT Health Education Center, The Fenway Institute; 2016. https://www.lgbthealtheducation.org/publication/ providing-affirmative-care-patients-non-binary-gender-identities/.

15. Koehler A, Eyssel J, Nieder TO. Genders and individual treatment progress in (non-)binary trans individuals. J Sex Med. 2018;15(1): 102-113.

16. Potter J, Peitzmeier SM, Bernstein I, et al. Cervical cancer screening for patients on the female-to-male spectrum: a narrative review and guide for clinicians. J Gen Intern Med. 2015;30(12):1857-1864. 